\title{
Cerebrovascular complications of diabetic ketoacidosis in children
}

\author{
Complicaçōes cerebrovasculares da \\ cetoacidose diabética em crianças
}

Luis Felipe Mendonça de Siqueira'

${ }^{1}$ Hospital das Clínicas, Universidade Federal de Minas Gerais (UFMG); Department of Pediatrics, Faculty of Medicine, UFMG, Belo Horizonte, MG, Brazil

\section{Correspondence to:}

Luis Felipe Mendonça de Siqueira Av. Professor Moraes, 532/82 30150-370 - Belo Horizonte, MG, Brazil

luismensiq@medicina.ufmg.br

Received on Jul/24/2010

Accepted on Apr/26/2011

\section{SUMMARY}

Neurological deterioration in children with diabetic ketoacidosis (DKA) is commonly caused by cerebral edema. However, subtle cerebral injuries including strokes should also be suspected, since children with hyperglycemia and DKA are prone to thrombosis. In this paper, a case involving a 2 month-old patient that presented cerebral edema and stroke as complications of DKA is reported. In the discussion, the literature on neurological complications of DKA in children is briefly reviewed, emphasizing the prothrombotic tendency of these patients. Arq Bras Endocrinol Metab. 2011;55(4):288-90

\section{SUMÁRIO}

Alterações neurológicas em crianças com cetoacidose diabética (CAD) são comuns, sobretudo em decorrência de edema cerebral. Contudo, lesões cerebrais agudas, como acidente vascular cerebral (AVC), também devem ser investigadas, já que as crianças com hiperglicemia e cetoacidose têm maior chance de apresentar essa complicação. Neste relato, descreve-se a história de um paciente de 2 meses de idade que apresentou edema cerebral e AVC como complicações de um quadro de cetoacidose diabética. Durante a discussão, será feita uma breve revisão da literatura sobre as complicações neurológicas da CAD nos pacientes pediátricos enfatizando sua tendência pró-trombótica. Arq Bras Endocrinol Metab. 2011;55(4):288-90

\section{INTRODUCTION}

C hildren with new onset type 1 diabetes mellitus $\checkmark$ (T1DM) frequently have diabetic ketoacidosis (DKA) as their initial presentation, a disorder that is associated with significant morbidity and mortality. In this context, neurological complications, including cerebral edema and other subtle cerebral injuries have long been recognized as the most frequent serious complications of DKA in children.

Indeed, acute injuries during brain maturation can result not only in neurological deficits but may also directly interfere with skills acquisition and psychological development of children with TIDM. This paper presents the case of a 2-month old infant who showed edema of the central nervous system and ischemic/hemorrhagic stroke as complications of DKA.

\section{CASE REPORT}

A previously healthy 68 day-old male infant was admitted in the emergency room with dehydration and som- nolence. The symptoms had started about one hour before, with vomiting, abdominal pain and deep, gasping breathing. Despite his altered level of consciousness, he was afebrile, normotensive and had normal parameters in general and neurological examination. After his first evaluation, he presented a 5-minute episode of right-sided focal seizure. Laboratory investigations showed ketonuria, acidosis ( $\mathrm{pH} 7.13$, bicarbonate $7 \mathrm{mmol} / \mathrm{L}$ ) and hyperglycemia (plasma glucose $480 \mathrm{mg} / \mathrm{dL}$ ). His brain computed tomography (CT) scan showed global cerebral edema.

He was taken to intensive care unit for metabolic stabilization and did not present hemodynamic instability or hypoxemia at any moment. He received fluid resuscitation, including a saline bolus $(10 \mathrm{ml} / \mathrm{kg})$ and intravenous fluids. He also required an intravenous bolus of midazolam and phenobarbital for acute management of seizures. An insulin infusion began in 0.05 units $/ \mathrm{kg} / \mathrm{h}$ and was maintained for $24 \mathrm{~h}$, followed by subcutaneous $\mathrm{NPH}$ insulin therapy twice daily $(0.3$ units $/ \mathrm{kg} /$ day $)$. Sodium bicarbonate was not used to treat acidosis. 
On the third day, left hemiparesis was noted and a new brain CT was performed, showing bilateral asymmetrical parieto-occipital areas of hypodensity and hyperdensity, compatible with ischemic/hemorrhagic infarction of slight preponderance on the right side. Screening for prothrombotic conditions showed negative results. After 12 days of hospitalization to select the right dose and timing of insulin therapy, he was released in good clinical and neurological recovery.

Over the next months of follow-up, phenobarbital was changed to valproic acid (44 mg/ $\mathrm{kg} /$ day), and physical therapy, occupational therapy and speech therapy interventions started promptly for appropriate habilitation and rehabilitation of the patient.

At six months of age, he had axial hypotonia and was not able to sit on his own. He also had soft left hemiparesis with left patellar hyperreflexia, although he presented good cognitive development, with normal auditory and visual reactivity. His head circumference, weight and length were between the $25^{\text {th }}$ and $50^{\text {th }}$ percentile in the NCHS growth charts. His sleep electroencephalogram showed an organized background, with no epileptiform discharges.

At the age of one year, he had normal language and social skills, was able to stand alone but could not walk by himself. He still had discrete left hemiparesis, but his axial tonus and patellar reflexes were normal. His cranial magnetic resonance imaging was compatible with the diagnosis of old ischemic/hemorrhagic bilateral parieto-occipital stroke (Figures 1 and 2).

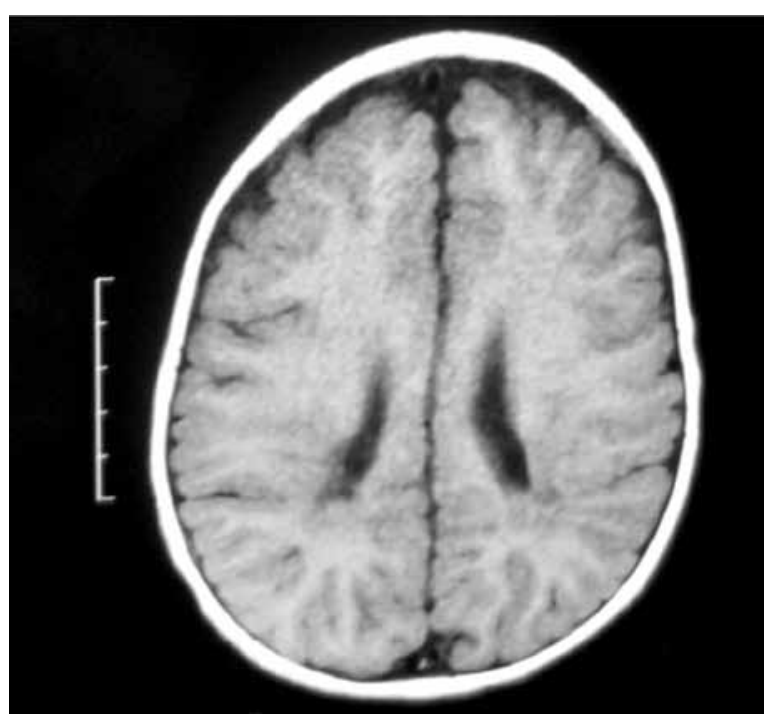

Figure 1. T1 weighted image - Discrete areas of hyposignal affecting bilaterally the periventricular parieto-occipital white matter (cavitations).

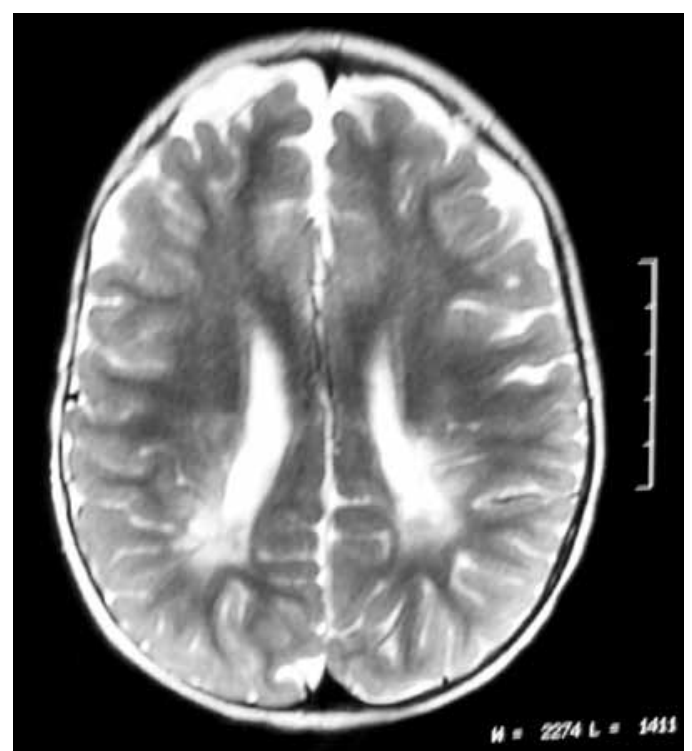

Figure 2. T2 weighted image - Almost symmetrical areas of hyperintensity affecting bilaterally the semioval center and the periventricular parietooccipital white matter.

Currently, the patient is 1.6 years old and on two doses of NPH insulin $(0.32 \mathrm{IU} / \mathrm{kg} /$ day $)$. His most recent HbAlc level measurement was 7.2\%. He still has a very discrete distal left leg weakness, but already walks very well, climbs stairs, speaks several words and has, therefore, normal psychomotor development.

Diagnosis of a genetic syndrome associated with neonatal diabetes was considered improbable, since the child presented good weight gain, absence of dimorphisms, good recovery from neurological deficits, progressive acquisition of developmental milestones, and his epileptic syndrome was classified as focal symptomatic epilepsy due to stroke, discarding diagnosis of progressive encephalopathy, and pointing to secondary neurological complications of DKA.

\section{DISCUSSION}

Cerebral edema is a major cause of serious complications in children with DKA. The first large population-based prospective study on this subject was published in 2001, and estimated risk of cerebral edema was 6.8 per 1,000 cases of DKA. Cerebral edema was also associated with significant mortality $(24 \%)$ and morbidity (35\% of survivors) (1).

In addition, other causes of neurological deterioration have been described in association with DKA. In a retrospective study with 69 pediatric patients with neurological complications, CT scans and post-mortem 
studies showed that approximately $20 \%$ of the patients were found to have localized basilar edema, hemorrhage, thrombosis or infection (2). Some case reports on cerebral and systemic infarctions associated with TIDM have also been published, all of them emphasizing the low probability of occurrence of the disorder, and the importance of early diagnosis, investigation and treatment for patients that present new onset TIDM and stroke with DKA (3-5).

The causes of the hypercoagulable state and endothelial dysfunction in TIDM patients are still unclear. However, evidence of increased thrombin-antithrombin complex, plasma factor VII coagulant activity, and D-dimers, besides increased intima-media thickness of the carotid artery were found in children with $\operatorname{TIDM}(6,7)$.

Several other haemostatic changes that could lead to a thrombotic tendency during DKA have also been identified, including evidence of endothelial injury, activation of platelets and relative hypofibrinolysis. It was also reported that children with severe DKA develop decreased protein $\mathrm{C}$ activity and elevated levels of von Willebrand factor (vWF) antigen and vWF activity, both before and during DKA treatment.

Besides, both hyperglycemia and DKA were reported to be accompanied by a proinflammatory state with elevated levels of cytokines, which also predispose to an acquired procoagulant state in in vitro and in vivo studies. Fortunately, after DKA treatment, platelet activity returns to normal and all the other measures of hemostasis improve (8-10).

This data supports the concept that cerebral thrombosis can occur unrelated to clinical cerebral edema, and that cerebrovascular dysregulation occurs at several sites during DKA and its treatment. Thus, it is likely that cerebrovascular accidents in children with DKA are diverse in their pathophysiology. In the case analyzed here, it is assumed that the hypercoagulable state was responsible for the stroke (8-10).

In summary, although the major cause of neurological deterioration in patients with DKA is cerebral edema, practitioners must also consider stroke in differen- tial diagnosis, especially in patients with focal findings, because of their prothrombotic tendency. DKA patients require close monitoring of their neurological status for at least $48 \mathrm{~h}$ after presentation, even if metabolic derangements have normalized. However, studies involving a multi-specialty approach are still needed to develop strategies to improve the outcomes for children with cerebrovascular events caused by DKA (11).

Disclosure: no potential conflict of interest relevant to this article was reported.

\section{REFERENCES}

1. Edge JA, Hawkins MM, Winter DL, Dunger DB. The risk and outcome of cerebral oedema developing during diabetic ketoacidosis. Arch Dis Child. 2001;85:16-22.

2. Rosenbloom AL. Intracerebral crises during treatment of diabetic ketoacidosis. Diabetes Care. 1990;13:22-33.

3. Lee HS, Hwang JS. Cerebral infarction associated with transient visual loss in child with diabetic ketoacidosis. Diabet Med. 2011;28(5):516-8

4. Reverter JL, Reverter JC, Tassies D, Rius F, Monteagudo J, Rubiés-Prat $\mathrm{J}$, et al. Thrombomodulin and induced tissue factor expression on monocytes as markers of diabetic microangiopathy: a prospective study on hemostasis and lipoproteins in insulin-dependent diabetes mellitus. Am J Hematol. 1997;56:93-9.

5. Roe TF, Crawford TO, Huff KR, Costin G, Kaufman FR, Nelson MD Jr. Brain infarction in children with diabetic ketoacidosis. J Diabetes Complications. 1996;10(2):100-8.

6. Giusti C, Schiaffini R, Brufani C, et al. Coagulation pathways and diabetic retinopathy: abnormal modulation in a selected group of insulin dependent diabetic patients. $\mathrm{Br} \mathrm{J}$ Ophthalmol. 2000;84(12):591-5.

7. Ileri NS, Buyukasik Y, Karaahmetoglu S, Ozatli D, Sayinalp N, Ozcebe Ol, et al. Evaluation of the haemostatic system during ketoacidotic deterioration of diabetes mellitus. Haemostasis. 1999;29:318-25.

8. Carl CF, Hoffman WH, Passmore GG, Truemper EJ, Lightsey AL, Cornwell $\mathrm{PE}$, et al. Diabetic ketoacidosis promotes a prothrombotic state. Endo Res. 2003;29:73-82.

9. Hoffman WH, Burek CL, Waller JL, Fisher LE, Khichi M, Mellick LB. Cytokine response to diabetic ketoacidosis and its treatment. Clin Immunol. 2003;108:175-81.

10. Van der Poll T, Buller HR, ten Cate $\mathrm{H}$, Wortel $\mathrm{CH}$, Bauer KA, van Deventer SJ, et al. Activation of coagulation after administration of tumor necrosis factor to normal subjects. N Engl J Med. 1990;322:1622-7.

11. Ho J, Pacaud D, Hill MD, Ross C, Hamiwka L, Mah JK. Diabetic ketoacidosis and pediatric stroke. CMAJ. 2005;172(3):327-8. 